\title{
The Abstract Form Analysis of Math Concepts Based on The Multiple Representation for Pre-Service Teacher
}

\author{
Case Study in Creating Math Manipulatives
}

\author{
Siti Khoiruli Ummah \\ Department of Mathematics Education \\ University of Muhammadiyah Malang \\ Malang, Indonesia \\ khoiruliummah@umm.ac.id
}

\begin{abstract}
This study aimed to analyze the math concept based on multiple representation. This study conducted in creating physical manipulatives activities of pre-service teachers. The method used in this study is descriptive method in the form of case study during the lesson in a semester. The data taken from the physical manipulative that have been created by preservice teacher. The data was adjusted from the kind of physical manipulatives, based on the multiple representation that were physical, pictorial, and virtual. The result of the study were the preservice teacher could not create the physical manipulatives that used the true math concepts, the most multiple representation that appeared was pictorial and physical manipulative, and the preservice teacher could not use the right mathematical fact and principes in creating physical maipulatives.
\end{abstract}

Keywords-abstract form; math concepts; multiple representation; manipulatives

\section{INTRODUCTION}

Mathematics has the specific characteristics that is having the abstraction of mathematics concepts. This characteristics could be said as the fundamental part of mathematics learning. The mathematical learning have to accommodate the ability of mathematical concepts (further it will be written by 'Math Concepts') through visual or concrete things. This would be called by math manipulative. The abstraction in mathematics then could be complex and it has been conducted by researchers $[1,2,3]$

Abstraction could be defined as the process of learning the abstraction of math idea, objects or concepts [4]. These process could be integrated in learning through empirical abstraction and mathematical abstraction. The fundamental learnings step was creating manipulatives. There are many studiy that concerned in creating math manipulatives related to abstraction process. The study aimed to improve the student's activity, student's positive attitude, problem solving, provide an additional resource in learning mathematics, connect with real-world, and improving memory and understanding $[5,6,1]$.

In mathematics, the pre-service teacher had to understand about content knowledge and curricular knowledge. Content knowledge means the pre-service teacher must be have knowledge of the specific subjects and how he/she organize the structure of the subject $[7,8,9,10]$. The content knowledge of the specific subjects are facts and concepts. Facts in mathematics related to symbol that often used in mathematical statement. Concepts in mathematics mean the set of facts. Organizing the structure of the objects usually related to principles that contained concepts and skills that established what is legitimate to do and say in a field. From the description, it could be stated that being a teacher have to understand and have a knowledge of the specific subject and implement the knowledge. It could be usefull to represent and formulate the subject and make it comprehensible to others.

Improving skill of the knowledge, teacher could create math manipulatives in order to represent concretely. It is aimed to make students learn and connect the concepts to specific subject,that is mathematics. It slaso could present the curriculum through multiple representations.

The purpose of this study is describing the math manipulatives that has been created by pre-service teacher. The math manipulatives that has been created would be analyzed based on the representation (concrete, static visual, and dynamic electronic) and the effectiveness from the ability to explain how the abstract form could present the math concepts.

This paper will show the math manipulatives that has been created by pre-service teacher. The math manipulatives should be balance of making a beautiful math manipulatives and could be implemented effectively. First, study regarding math manipulatives that has been created is reviewed. This aimed to know how manipulatives in school implemented or the use of math manipulatives in school. Then, the pre-service teacher find the solution through making math manipulatives to transfer knowledge or abstract concepts to concrete. Lastly, the math manipulatives is presented by pre-service and encourage the other pre-service teacher to implement the transfer knowledge in concrete to abstract form. 


\section{Math Manipulatives}

\section{A. Physical Manipulatives}

Physical Manipulatives is usually called by concrete manipulatives. It could be folded, cutted, pasted, rotated, and moved. Mnaipulatives also could be found in daily life or formed from the things that around human. It could be like paper, ribbon, ball, tooth picks, money, string, playing card, dominoes, cartons, cups, plate, pipes, buttons, pins, seeds, sterofoams, and candies. The combined things could be make a specific manipulatives for specific mah content, such as dominoes for linier equation, monopoli, bar graph, or bulletin board. Usually, the physical manipulative could be interactive directly for the users. The students or teacher as users used the manipulative by moving or arranging by hand as means developing understanding abstractions or motor skills in mathematics [11, 12].

The physical manipulatives also referred as dynamic because formed physical objects. The physical manipulative could transfer the ability to create, interpret, use, and reflect on images in the mind, on paper, or bulletin board [13]. It could be displayed the levels of spatial visualization [14], presents opportunities for constructing mathematical knowledge [15], assist students in developing a solid understanding of mathematical concepts [16], and visualize mathematics concepts beyond the use of the virtual manipulatives [17].

\section{B. Static Manipulatives}

The static manipulatives could be referred to pictorial manipulative that could be drawn and created a concepts. The benefit of using static manipulatives are gaining a better understanding of the problem [18], lacking the tangible and dynamic attributes of physical manipulative [19], being an effective method for modelling the operations of integers [20]. Based on the study of the researcher, Low-achieving students worked with mathemarics symbols on pictorial representations [21].

\section{Virtual Manipulatives}

The virtual manipulatives referred to computer based of mathematics manipulatives [22]. The other form of virtual manipulatives is web-visual representation [23]. The benefit of virtual manipulatives are students caould connect the words, pictures, colors, and symbols simoultaneously. It could be referred as dynamic manipulatives because the user could play the manipulatives interactively. Virtual anipulatives use two dimensional and digital based on computer program. The program usually used Adobe Flash, Microsoft Power Point, Matlab, Matcad, Flipbook or other program to create animation. The getter animation could attract or motivate students to follow the instructions and the exercise that will be served by virtual manipulatives. It would be better from the other kind of manipulatives because could bring everywhere practically. It also could save in the form of application and could be accessed in mobile phone. The form of virtual manipulatives are games, presentation, digital book, comic, or folk tales using animations.

\section{RESEARCH METHOD}

The research method used qualitative research that used qualitative data to be described. The data was description about the manipulative that has been created by students in mathematics department Academic Year 2016. The description based on the fact what kind of manipulatives that has been created, physical, static, or virtual.

\section{A. Research Subject}

The research subject of the study were students of mathematics department Academic Year 2016. They has been divided by groups whose members are two. Each group had to create the math manipulative using things around them and easily found in daily life. The manipulatives material could not be more than one hundred thousand rupiahs. They also could find the materials from used good such as drinking bottles, bottles cap, cartons, wood, string, or patchwork.

\section{B. Research Prosedure}

First, student divided into groups and content of math in secondary school. The content of math based on Curricula 2013 that has been stated by the government. The students chosen the member of the group used the rule "the member didn't allowed by the the same gender". Then, students will be informed about the manipulatives criteria based on the reference that has been discussed in the last meetings.

Second, students tried to create the manipulatives. Before they created it, students must be create the storyboard of the manipulatives. The storyboard contained the name of manipulatives, content of math, learning indicators, materials, descriptions of creating manipulatives, and the use of the manipulatives. The storyboard must submitted before the manipulatives will be presented.

Third, students had to create the manipulatives in about three weeks. They could consulted their manipulatives to the lecturer bringing their video or photo of manipulatives.

Fourth, the students must be present their manipulatives. The presentation about the name of manpulatives and practice the manipulative. The effectiveness of manipulative could get from how the user (other students) could operate the manipulatives. The other students also assess the manipulative that has been made by presenter.

\section{Data Analysis}

The data analysis could be done by reduction and analyze data. The reduction based on the kind of manipulatives that has been created by students. After that, the researcher analyze data using description about the manipulatives. The description contained the truth of concepts that has been presented by students, the understanding of manipulatives maker about the use of manipulatives, and the aesthetics of manipulatives that could be seen by color combination, shape, and the durable of manipulatives. The manipulatives could be attracted the user seen by the attention of the other students.

\section{Data Instrument}

The data instrument are the form of storyboard and field note. The researcher also serve the assessment format for students. 


\section{RESULT AND DISCUSSION}

The results would be displayed by description of each kind of manipulatives that has been created by students. The discussion would be described by comparing the result of these study to the previous study.

\section{A. Physical Manipulatives Product}

The example of physical manipulatives were based on math content that is the distance speed formula. Media created used ink markers, wood, plank path, and toy cars. The concept of comparative worth and turn the value are delivered by the teacher directly. There are constraints at a time when the media are operated i.e. ink can not stick perfectly on board trajectory. In the first experiment that is worth a comparison, the car was given the ink is then run on a path with a certain slope. The ink spots were then measured using a ruler according the round wheel. The more round the wheel then the length of the distance traveled by car. Car media assisted sheets of paper in the form of table measuring results so that users of the media noted the results of the experiments on the table. In the second experiment, i.e. the comparison turned media value, using the difference in size of the slope of the path Board with car travel time. There are constraints on the second trial that is not on the path of the oncoming cars so get out of the path. The more the pile then the reduced journey time cars on the same lap. The concept of comparison has been very appropriate with the learning media being used. However, the use of paper as a media reporter experiment results too small so that less can look when presented. The path used to use plastic material so that ink traces can be removed.

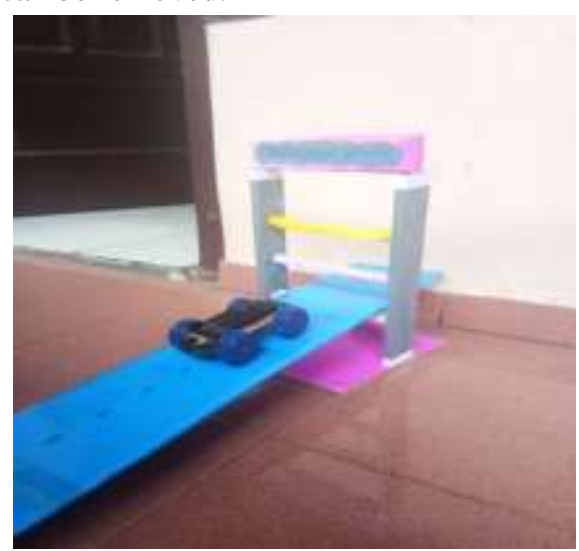

Fig. 1. The Path Comparison (An Example of Physical Manipulative)

The Path Comparison based on Fig. 1 is adapted from the manipulatives that has been researched by other researcher. The students could operate the car and modify the board that has a different height. The students also erase the ink on the board so the media could be durable. The students could move the car and the board easily. It was relevant to [17] that the physical manipulatives could be moved easily.

The lack of the media is the paper as a media reporter experiment not include in the manipulatives. The students should serve the board to make the experiment report so that the other students could see clearly. The manipulatives also has not contained the tittle of media. The side of board for car landing should be bounded by adding the board in two-sides.

The understanding concept of comparison could be explained well. The students who create the manipulatives explain from two different experiment. The first experience is comparing time to speed then the second experience is comparing the distance to the total number of rounded wheel. The wheels could be said by one round if the car mark using ink spot on board. The different distance is comparing by the different height of the board.

\section{B. Pictorial Manipulatives Product}

The exampleof pictorial manipulative learned intersection, union, and two difference sets. Manipulative using sterofoam which describes the operating range of the third set. The concept of a union sets and illustrations used only through a different form of sterofoam so that users have not been able to construct the concept of combined and sliced on the set. The media are exercise questions with retractable media properties, pasting and replaced with other forms of sterofoam. The use of color is interesting because there are a variety of colors that contrast. Learning media still need help teachers in their use. The concept of two sets have not been appropriate because in making a venn diagram there is no naming of each set. Paper to show the members of the set is quite wide so not contained entirely on the circle. The concept of the joint where the same members are written once and delivered by teachers not found by students and shown using only one image on the same slice. Learning media also has yet to show the contextual problems. the scope of the material that is used in the manipulative is limited to a intersections, union, and difference.

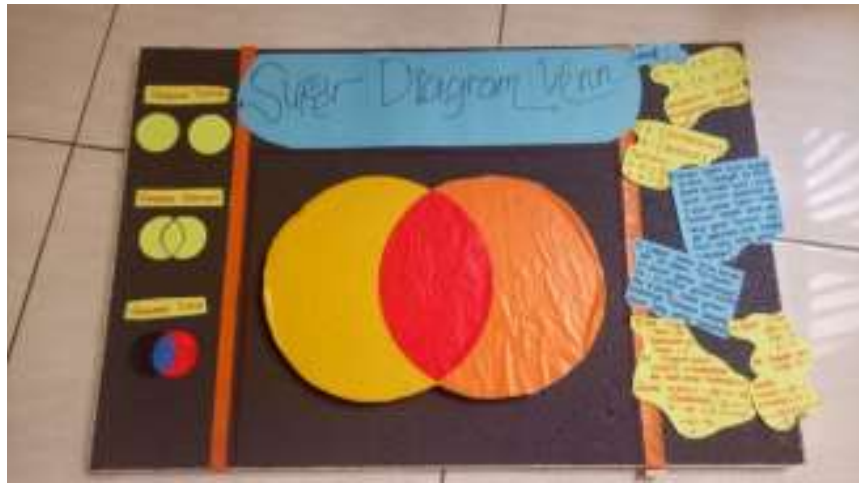

Fig. 2. Super Diagram Venn (An Example of Pictorial Manipulative)

The students could explain how the intersection set could be formed using manipulatives. The Diagram Venn has been served by the student. So, when the exercise did by another students, they only pick the suitable diagram that represented the sets operation. The students didn't construct the math content because all of definition of each sets operation could be seen in the right side of the manipulative.

\section{Virtual Manipulatives Product}

The example of virtual manipulative based on the math content that is spatial geometry. The math content focused on cube, rectangular prism, and triangle prism. The manipulative 
is very interactive because the users have to press the keyboard on notebook or PC. Virtual manipulative use Adobe Flash applications with a very interesting color combinations. Initially, the user is asked to listen to the content of media profile (the identity of the manufacturer of the media, an indicator of learning materials, and quizzes). The media also uses music as the backsound and use recording as a hint of its use. The user must press the button bottom arrow to run object in the form of a woman. Then the button arrow down to making objects jump. The concept of a game similar to Super Mario Bross game where the user must run the object until it comes to a certain objects. For example there is a picture of the dice that is above the object means a user must create an object skips so can pass the dice. After passing the dice, then there is a new window that brings out the characteristics of cubes. Characteristics provided i.e. be side, angle, and mesh cubes. Users are asked to listen to how the cube shaped nets so that it can identify elements of the cube. This will be the same as the deliberations of the rectangular prism and triangle prism.

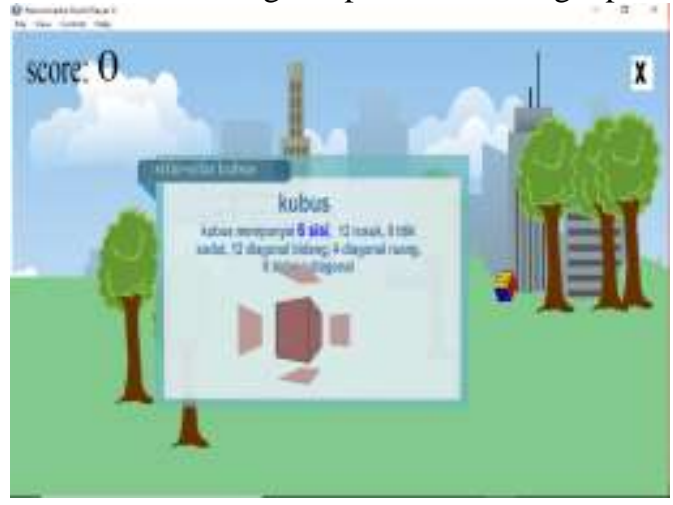

Fig. 3. Example of Virtual Manipulatives. (Cube)

The lack of these manipulatives i.e. image of cube cannot be known by students. This is because the media maker makes cubes with perspectives from the right-side. This will make students confused because students don't recognize the shape of a cube. In addition, when a cube of side separated, the form of cube side was not in the form of a square. Other lack of virtual manipulatives that is users cannot terminate the operations of the media at any given time. This is because the media makers using only one button in the form that appears and will be back at the main menu. In addition, each end of the discussion of the material given to question the conclusions of the evaluation in the form of material that has been discussed. Other deficiencies, namely, the question of the evaluation to be completed when students answer error occurs it will be back on the matter with reason in order that students listen to return the material that has been delivered. This will make the bored students because students cannot continue their journey before completing the entire process.

Three examples of math manipulatives described above, overall manipulatives accordance to its characteristics and has a beautiful art elements in terms of color combinations constituting. Physical manipulative exemplified already fit that is can be moved, rotated, and operated by hand [13]. Pictorial manipulatives are also made with how to display math symbols
[17]. Virtual manipulatives would also have been appropriate that is using computer applications and using animation [11].

Math concept has yet to make students understand well. This is evidenced by there are still existing faults and lack in the writing of mathematical symbols properly i.e. the concept of direct and inverse proportion concept. In addition, the concept of the set also has a write error symbol a mathematical symbol usage i.e. different sets symbolized by the complement of the set. The depiction of the cube is also less precise due to lack of students can be recognized. In addition, side doesn't use a square.

Students are also less able to maximum in making construction materials through manipulatives. This is demonstrated with the availability of media to obtain the correct answer. Examples of manipulatives, pictorial on students just asked looking shapes that correspond to the operation of the set. Students not be asked how to construct the set of slices can occur. In addition, in comparison, the material the student has not been able to make a straight path so when made the comparison value then turned the direction of the car not straight car distance that resulted in increased.

\section{CONCLUSION}

Manipulatives is suitable with the characteristics of a kind of manipulatives. Math concept has yet to be mastered students because there are still errors in mathematical representation symbolizing the concept in the form of pictures.

\section{REFERENCES}

[1] P. L. Ferrari, "Abstraction in mathematics," The Royal Society, vol. 358, pp. 1225-1230, 2003.

[2] D. T., Advanced Mathematical Thinking Processes: In Advanced Mathematical Thinking, Dordrecht: Kluwer, 1991.

[3] Deyfruz. T. E., "Abstraction: theories about the Emergence of Knowledge Structures," in Proc. 26th Ann. Conf. Int. Froup for Psychology of Mathematics Education, Norwich, 2002.

[4] F. Nurhasanah, "ABSTRAKSI DAN ALAT PERAGA MAYA DALAM PEMBELAJARAN MATEMATIKA," in Konferensi Nasional Pendidikan Matematika, At Unimed Medan, Medan, 2009.

[5] P. K. N. Iyer, "From Concrete to Abstract: Teaching for Transfer of Learning when Using Manipulatives," in Northeastern Educational Research Association (NERA) Annual Conference, Oneonta, 2009.

[6] N. \&. J. L. McNeil, "When theories don't add up: Disentangling the When theories don't add up: Disentangling the," Theory into Practice, vol. 46, no. 4, pp. 309-316, 2007.

[7] Deborah Loewenberg Ball et al., "Content Knowledge for Teaching : What Makes It Special?," Journal of Teacher Education, vol. 59, pp. 3899-407, 2008.

[8] P. L. W. Shulman. M. \&. S. L. S. Grossman, "Teachers of substance: Subject matter knowledge for teaching," in The 
knowledge base for beginning teachers, New York, Pergamon, 1989, pp. 23-36.

[9] J. Schwab, " Education and the structure of the disciplines.," in Science, curriculum, and Liberal Education, Chicago, University of Chicago, 1978, pp. 167183.

[10] S. L.Shulman., "Those who understand: Knowledge growth in teaching," Educational Researcher, vol. 15, no. 2, pp. 4-14, 1986.

[11] L. Cope, "Math Manipulatives: Making the Abstract Tangible," Delta Journal of Education, vol. 5, no. 1, pp. 1021, 2015.

[12] J. Bellonio, "Multi -Sensory Manipulatives in Mathematics: Linking the Abstract to the Concrete," 5 March 2012. [Online]. Available: http://www.cis.yale.edu/ynhti/curriculum/units/2001/6/01. 06.12.x.html. [Accessed 1512 2017].

[13] A. Arcavi., "The role of visual representations in the learning of mathematics," Educational Studies in Mathematics, vol. 52, no. 3, pp. 215-241, 2003.

[14] L.J Van Garderen., " Spatial visualization, visual imagery, and mathematical problem solving of students with varying abilities," Journal of Learning Disabilities, vol. 39, no. 6, pp. 496-506, 2006.

[15] P. Shulman. \&. J. M. G. Moyer, "Controlling choice: Teachers, students, and manipulatives in Mahematics Classroom," . School Science and Mathematics, vol. 104, no. 1, pp. 16-31, 2004.

[16] Paivio A., Mind and its evolution: A dual coding theoretical approach, Mahwah: Erlbaum, 2007.

[17] Patricia S. Moyer-Packenham, Lori A. Ulmer\&Katie L. Anderson, Examining Pictorial Models and Virtual Manipulatives for Third-Grade Fraction Instruction, vol. 11, no. 3, pp. 103-121, 2012.

[18] G. P. B. B. W. Musser, Mathematics for Elementary Teachers: A Contemporary Approach, 10th Edition, Wiley, 2014.

[19] National Governors Association Center for Best Practices, Common core state standards mathematics, Wahington D.C.: National Governors Association Center for Best Practices, Council of Chief State School Officers, 2010.

[20] P. Shulman. \&. S. J. M. Moyer-Packenham, "Learning mathematics with technology: The influence of virtual manipulatives on different achievement groups," Journal of Computers in Mathematics and Science Teaching, vol. 31, no. 1, pp. 39-59, 2012.

[21] Dorward. J., "Intuition and research: Are they compatible?," Teaching Children Mathematics, vol. 8, no. 6, pp. 329-332, 2002.

[22] P. S. Bolyard. J. J. \&. Spikel, "What are virtual manipulatives?," Teaching Children Mathematics, vol. 8, no. 6, pp. 372-377, 2002. 